\title{
A transformação da prática obstétrica das enfermeiras na assistência ao parto humanizado
}

\author{
The transformation of nurses' obstetrical practice in humanized birth care
}

Transformación de la práctica obstétrica de las enfermeras en la atención del parto humanizado

Karla Gonçalves Camacho ${ }^{1}$, Jane Marcia Progianti²

\footnotetext{
${ }^{1}$ Enfermeira, Mestre em Enfermagem. Enfermeira do Hospital Federal do Andaraí e do Hospital Naval Marcílio Dias. Rio de Janeiro, RJ, Brasil. E-mail: pequenakgc@yahoo.com.br.

${ }^{2}$ Enfermeira, Doutora em Enfermagem. Professora Adjunta da Faculdade de Enfermagem da Universidade do Estado do Rio de Janeiro. Rio de Janeiro, RJ, Brasil. E-mail: jmprogi@uol.com.br.
}

\section{RESUMO}

Este estudo qualitativo teve por objetivo descrever o processo de aquisição de práticas obstétricas hospitalares, pelas enfermeiras obstétricas, frente à implantação do modelo humanizado. Participaram do estudo 11 enfermeiras obstétricas de seis maternidades municipais do Rio de Janeiro/Brasil. Os dados foram coletados por meio de entrevistas, de janeiro a março de 2009, e analisados por meio da análise de conteúdo temática, tendo como base de diálogo os conceitos de Pierre Bourdieu. Os resultados apontaram que as enfermeiras pesquisadas incorporaram novos conhecimentos que foram agregados em seu habitus profissional, gerando práticas que as fizeram romper com a reprodução do modelo biomédico no campo obstétrico. Concluiu-se que muitas enfermeiras obstétricas no processo de implantação da política de humanização do parto e nascimento reconfiguraram sua prática obstétrica de cuidado, centrando-as no estímulo do protagonismo da mulher e no respeito à fisiologia do parto.

Descritores: Parto Humanizado; Saúde da Mulher; Enfermagem Obstétrica.

\section{ABSTRACT}

The objective of this qualitative study was to describe the practices performed by obstetrical nurses in hospitals, in view of the implementation of the humanized model for birth care. The participants were 11 obstetrical nurses from six municipal maternity hospitals in Rio de Janeiro/Brazil. Data were collected through interviews performed between January and March of 2009, and submitted to thematic content analysis based on the concepts proposed by Pierre Bourdieu. Results showed that the studied nurses incorporated new knowledge that were added to their professional habitus, creating practices that eventually broke with the reproduction of the biomedical model in the field of obstetrics. In conclusion, many obstetrical nurses restructured their obstetrical care practice when implementing the policy of humanized birth care, focusing their practice on encouraging the woman's leading role regarding birth physiology.

Descriptors: Humanizing Delivery; Women's Health; Obstetrical Nursing.

\section{RESUMEN}

Estudio cualitativo que objetivó describir el proceso de adquisición de prácticas obstétricas hospitalarias por parte de las enfermeras obstétricas, ante la implantación del modelo humanizado. Participaron 11 enfermeras obstétricas de seis maternidades municipales de Rio de Janeiro/Brasil. Datos recolectados mediante entrevistas, entre enero y marzo de 2009, analizados según análisis de contenido temático, teniendo como bases de diálogo los conceptos de Pierre Bordieu. Los resultados expresaron que las enfermeras estudiadas incorporaron nuevos conocimientos que fueron agregados a su habitus profesional, generando prácticas que las hicieron romper con la reproducción del modelo biomédico en el campo obstétrico. Se concluyó en que muchas enfermeras obstétricas, en el proceso de implantación de la política de humanización del parto y nacimiento, reconfiguran su práctica obstétrica de cuidado, enfocándolas en el estímulo del protagonismo de la mujer y en el respeto a la fisiología del parto.

Descriptores: Parto Humanizado; Salud de la Mujer; Enfermería Obstétrica. 


\section{INTRODUÇÃO}

Nos anos 90, intensificaram-se as críticas em nossa sociedade ao modelo biomédico obstétrico. Essas críticas fundamentavam-se em seu autoritarismo, não respeitando o direito de escolha das mulheres sobre seu tipo de parto, gerando nos profissionais de saúde práticas obstétricas intervencionistas. Consequente a essas críticas surgiu o movimento de humanização do parto e do nascimento, que interligado com o movimento feminista, defende a transformação desse modelo

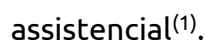

Nesse contexto, o modelo da humanização do parto e nascimento encontrou apoio na Organização Mundial de Saúde (OMS), que já em 1985, publicava o documento "Tecnologia Apropriada para Partos e Nascimentos", enfatizando os direitos da população em relação à assistência pré-natal e à informação sobre as várias tecnologias utilizadas no parto, descrevendo o papel das instituições de saúde em relação ao nascimento e fazendo críticas ao modelo biomédico, inclusive questionando a cientificidade das tecnologias e intervenções utilizadas no parto como rotina(2).

Sob a perspectiva do modelo humanizado, uma das possibilidades para reduzir a mortalidade materna estaria justamente em reduzir as taxas de cesarianas e, para tal, uma das estratégias seria inserir enfermeiras obstétricas na assistência para incentivar o parto vaginal implantando práticas baseadas em evidências científicas, o que gerou muitos conflitos no campo obstétrico, principalmente, com a corporação médica(3).

Desse modo, estabeleceu-se uma luta no campo obstétrico, que existe até o momento atual, onde de um lado, estão os defensores da manutenção do modelo biomédico e do outro, os que desejam a transformação do mesmo(3).

Para viabilizar a implantação de práticas obstétricas dentro do modelo humanizado, muitas enfermeiras foram estimuladas a participar desse processo, tanto que, em 1998, o Ministério da Saúde (MS) publicou duas Portarias que regulamentavam a assistência obstétrica prestada por enfermeiras. A Portaria № 2815 de 29/05/1998 que incluía na tabela do Sistema de Informações Hospitalares (SIH/SUS), os procedimentos para o parto normal sem distócia realizados por enfermeiras obstétricas e a Portaria GM № 163 de 22/09/1998(4), que regulamentou a realização do parto normal sem distócia por enfermeira obstétrica nas
Organizações de Saúde Públicas do Sistema Único de Saúde (SUS).

Especificamente na cidade do Rio de Janeiro, essas Portarias criadas no âmbito do Ministério da Saúde, contribuíram para que nesse mesmo ano, a Secretaria Municipal de Saúde (SMS-RJ), lançasse o Projeto de Implantação da Assistência de Enfermagem à Gestante e à Parturiente em duas grandes Maternidades Municipais com a finalidade de implantar práticas condizentes com o modelo humanizado de assistência ao parto(5).

Como impacto dessa política pública, temos que até o início do ano de 2000, quando foi lançado o Programa de Humanização de Pré-Natal e Nascimento (PHPN), as enfermeiras obstétricas da SMS-RJ, já assistiam a uma média de 30 a $40 \%$ de todos os partos vaginais de baixo risco em suas maternidades(6).

Por entendermos que muitas enfermeiras participaram ativamente do processo de implantação do modelo humanizado nas maternidades do Rio de Janeiro, e que essa participação foi num contexto de lutas, acreditamos que houve transformações significativas em sua prática obstétrica(7).

Assim, esse estudo teve por objeto as transformações das práticas obstétricas das enfermeiras no campo obstétrico hospitalar e por objetivo descrever o processo de aquisição dessas práticas frente à implantação do modelo humanizado em maternidades públicas do Rio de Janeiro.

Este estudo contribuirá com as políticas públicas porque, ao proporcionar a compreensão do processo de aquisição de novas práticas em um grupo profissional, será possível uma reflexão no sentido de orientar as ações para o futuro, principalmente no que diz respeito à implantação de novas tecnologias no Sistema Único de Saúde.

\section{METODOLOGIA}

Estudo de abordagem qualitativa onde utilizamos como técnica de pesquisa a história oral temática. A história oral permite reproduzir acontecimentos do passado e do presente vivenciadas por indivíduos por meio de entrevistas gravadas ${ }^{(8)}$.

Os sujeitos do estudo foram 11 enfermeiras que atenderam aos critérios de inclusão: ter concluído o curso de especialização em enfermagem obstétrica em Instituição de Ensino Superior pública ou privada; estar no momento da pesquisa atuando na assistência ao parto em 
instituições hospitalares. Foram excluídas do estudo: enfermeiras que atuavam em Casas de Parto por considerar que nessas Unidades, a prática de enfermeiras obstétricas é muito específica.

Assim, os cenários da pesquisa foram seis maternidades municipais pertencentes à Secretaria Municipal de Saúde (SMS-RJ), que tinham após a implantação da política de humanização, enfermeiras obstétricas atuantes na assistência direta ao parto e nascimento.

A coleta de dados foi realizada entre os meses de janeiro a março de 2009, utilizando entrevistas semiestruturadas, gravadas em MP3. Para orientar a realização das entrevistas foi elaborado um roteiro, que abordava o sujeito da pesquisa da seguinte maneira: Faleme sobre sua prática obstétrica ao longo de sua vida profissional.

A análise dos dados foi realizada a partir da análise de conteúdo das narrativas, que na modalidade temática desdobra-se nas etapas de pré-análise (leitura flutuante, constituição do corpus e transcrição); exploração do material (categorização dos dados mediante a leitura exaustiva das entrevistas transcriadas); e tratamento dos resultados obtidos e interpretação( ${ }^{(8)}$. Seguindo estas etapas, foram elaboradas duas categorias: o ensino e a prática da enfermagem obstétrica antes da Implantação da Política de Humanização do Parto e Nascimento e o ensino e a prática da enfermagem obstétrica após a Implantação da Política de Humanização do Parto e Nascimento.

Na análise final os dados foram interpretados à luz do conceito de habitus de Pierre Bourdieu ${ }^{(9)}$. Nesse sentido, - estudo entende a prática desenvolvida pelas enfermeiras, como pertencente ao seu habitus profissional e por isso mesmo, ela é um saber agir aprendido pelo agente na sua inserção em determinado campo, sendo que as estruturas do campo são importantes para a formação do mesmo, porém não determinantes para a ação dos agentes.

Sendo assim, o habitus é construído socialmente e é um sistema de disposição aberto, que é incessantemente confrontado por experiências novas e, assim, incessantemente afetado pelos contextos sociais e pela distribuição do poder(10).

O habitus dos sujeitos tanto pode gerar uma prática como pode transformar suas práticas, dependendo da inserção e da movimentação destes em seus campos sociais, por meio das lutas travadas entre os indivíduos dentro destes espaços ou por uma análise reflexiva sobre suas próprias disposições ${ }^{(11)}$.

Os sujeitos foram esclarecidos sobre os objetivos da pesquisa e assinaram o Termo de Consentimento Livre e Esclarecido e o Termo de Cessão de Direitos sobre o Depoimento Oral para a doação das entrevistas ao Centro de Memória Nalva Pereira Caldas da Faculdade de Enfermagem da Universidade do Estado do Rio de Janeiro. O estudo foi encaminhado ao Comitê de Ética em Pesquisa da Secretaria Municipal de Saúde do Rio de Janeiro, com os devidos Termos acima anexados e foi aprovado no Parecer № 273-A do Protocolo 210/08.

Na época da coleta de dados, as entrevistas foram identificadas por um código representado pela letra "E" e uma numeração de 01 a 11, por ordem de realização das mesmas pelas autoras, a fim de preservar a privacidade dos sujeitos.

\section{RESULTADOS E DISCUSSÃO}

Ao relatarem sobre sua prática obstétrica, abordaram o processo de aquisição dessas práticas frente à implantação do modelo humanizado em maternidades públicas do Rio de Janeiro. Nesse processo, as enfermeiras pesquisadas descreveram como era o ensino e a sua atuação antes e após sua inserção nas políticas de humanização do parto e do nascimento.

\section{O ensino e a prática da enfermagem obstétrica antes da Implantação da Política de Humanização do Parto e Nascimento}

Antes da implantação da Política de Humanização do Parto e Nascimento pela SMS-RJ, na cidade do Rio de Janeiro, a grande maioria das enfermeiras pesquisadas que atuavam no campo obstétrico, reproduziam a obstetrícia clássica com o modelo biomédico hospitalar, ou seja, medicalizado:

A gente aprendia e ensinava obstetrícia no modelo tradicional médico. (Entrevista 01)

Neste contexto, as escolas de enfermagem também contribuíram para fortalecer e reproduzir esse modelo no campo obstétrico, pois ensinavam para as enfermeiras a obstetrícia dos livros médicos: 
Eu aprendi obstetrícia no livro que é médico e com o médico, quando eu fui fazer enfermagem obstétrica. (Entrevista 10)

As enfermeiras que atuavam junto à parturiente, reproduziam o que aprendiam em sua formação acadêmica, voltada para a prática obstétrica hospitalar:

Elas trabalhavam junto com os médicos e a assistência era basicamente a mesma, tinha aquela questão da dieta zero, da gestante ter que ficar no leito. O que os médicos faziam as enfermeiras faziam. (Entrevista 05)

Nesta época, podemos dizer que as enfermeiras não estavam atuando para mudar a assistência ao parto, pois não tinham uma visão de mundo diferenciada no espaço hierarquizado hospitalar. Nesse contexto, os que ocupavam melhores posições ditavam o jogo e os agentes sociais só conseguem participar do jogo específico de cada campo se estiverem dotados de um mínimo de capital específico ${ }^{(11)}$.

Essas concepções não geravam práticas que pudessem distinguir as enfermeiras no campo e muitas enfermeiras não atuavam nessa área, mesmo sendo especialistas em enfermagem obstétrica.

Foi possível observar que com o capital incorporado via formação, antes do processo de humanização, muitas enfermeiras demonstraram que apenas reproduziam as mesmas concepções presentes na prática obstétrica médica, contribuindo para manter a ordem instituída(3). Neste momento, predominavam as relações assimétricas, sem a escuta ativa do cliente, sem que a mulher ocupasse sua real posição de protagonista no processo do nascimento:

Eu venho do modelo biomédico, saturado do poder, você decidia o que fazer, como fazer, que horas fazer, sem ter a mulher como participante desse processo decisório. (Entrevista 04)

Elas mostraram em suas falas que viam a mulher em uma posição de paciente, ser passivo, não atuante, sem desejos, sem vontades, não protagonista de sua própria história no processo de parto e nascimento:

Antes eu via a mulher como uma paciente, e como paciente, ela tinha que fazer o que a gente queria. Então hoje eu já não veja assim, vejo como um indivíduo que tem desejos, que tem vontades [...](Entrevista 4)

Quando eu comecei, nós assistíamos ao parto [...] quando tinha uma equipe médica por perto [...] fazia episiotomia [...] de rotina em primípara [...] eu fazia porque era uma cobrança, até mesmo do pediatra para fazer episiotomia. (Entrevista 07)

Sendo assim, observamos que não houve até então a mudança de habitus e nem a aquisição de um capital específico pelas enfermeiras obstétricas, pois a formação oferecida não gerava mudanças de ações, práticas, e nem de posição dentro do campo obstétrico.

\section{O ensino e a prática da enfermagem obstétrica após a Implantação da Política de Humanização do Parto e Nascimento}

As habilidades específicas de um agente é um saber agir aprendido mediante sua inserção em determinado campo, sendo que as estruturas do mesmo são importantes para sua formação, porém não determinantes para a ação dos agentes ${ }^{(9)}$. Deste modo, as enfermeiras pesquisadas perceberam que a realidade de sua prática obstétrica começou a mudar na cidade do Rio de Janeiro, no final da década de 90, inicialmente com o reconhecimento do Estado brasileiro de sua atuação no parto e nascimento ${ }^{(12)}$ :

Eu acredito que se essa determinação (para inserção das enfermeiras obstétricas no parto) [...] se não tivesse partido de cima, apoiada pelo governo aqui do município do Rio, teria sido mais difícil essa prática da enfermagem obstétrica [...] mas se isso não tivesse escrito no papel em forma de lei teria sido muito difícil, praticamente impossivel. (Entrevista 05)

As entrevistadas, além de destacarem a significativa participação do Estado, também reconhecem a importância do papel dos gerentes locais na mudança e reconhecimento do projeto de humanização:

Então eu acredito nisso: o apoio dos gestores, o material humano e a disposição são necessários para que se faça a mudança dos paradigmas assistenciais. Isso é fundamental. [...] Você sem apoio, você não consegue caminhar, você não consegue desenvolver o seu trabalho por melhor que ele seja, por mais qualificado que você seja, por mais resultados 
que você consiga obter. Se você não tiver apoio você não chega a lugar nenhum. (Entrevista 04)

O apoio dos gerentes foi fundamental, até porque as condições de acumulação de capital são proporcionais às oportunidades de jogo que os agentes encontram nos campos sociais, e neste caso os gestores estavam fornecendo novas oportunidades de jogo a estes atores.

É necessário que os gestores estejam unidos em torno dessa proposta, [...] Você vê que a questão é realmente de gestão, porque você vê outras unidades onde aqueles gestores que estavam lá que foram para lá, você vê que nessas unidades o trabalho floresceu, o trabalho cresceu, o trabalho fortaleceu e segue até hoje. Então, você tem de perceber que é uma questão realmente política, não apenas de trabalho, de botar a mão na massa, é uma questão política, uma questão de bancar. (Entrevista 04)

Percebemos que neste caso as oportunidades geradas pelos gestores não poderiam ser circunstanciais ou aleatórias, estavam balizadas pelo volume e estrutura de capital dos agentes, relacionadas com o volume e estrutura de capitais dos demais agentes envolvidos no jogo específico do campo obstétrico(6).

Essas oportunidades atendiam tanto aos interesses dos gestores em diminuir as intervenções e seus efeitos nocivos ao parto, como também aos movimentos sociais que defendiam o protagonismo e a autonomia das mulheres. A defesa do protagonismo e da autonomia das mulheres se constituiu numa oposição ao autoritarismo médico presente nas práticas obstétricas das maternidades do Brasil.

A implantação de uma política pública pode transformar práticas porque atualiza o habitus profissional dos profissionais envolvidos no jogo, com a aquisição de novos capitais que geram novas disposições dos sujeitos dentro do campo. A disposição incorporada leva o indivíduo a agir como um membro típico de um grupo, ocupante de uma posição dentro do campo, de tal forma que este agente sente-se ajustado a fazer com naturalidade suas ações ${ }^{(7)}$.

Assim, as enfermeiras pesquisadas, mudaram sua visão de mundo quando entraram em contato com a obstetrícia orientada pelos princípios do modelo humanizado e passaram a ser orientadas pelo respeito humano(13):
Eu acho que eu só tive a ganhar quando tive contato com a nova obstetrícia [...] A humanização parte de um pressuposto do respeito ao outro como individuo, de seu espaço, seu querer, sua vontade, seu desejo de alguma coisa. (Entrevista 04)

As enfermeiras relataram que alguns Cursos de Especializações em Enfermagem Obstétrica, Congressos e Encontros também contribuíram para o processo de incorporação dos princípios de humanização como um saber que gerou novas práticas:

Em 2004 eu tive um contato mais profundo com a questão da humanização através da especialização que tem a humanização como o seu alicerce, então foi quando eu comecei a ter um contato mais profundo com os princípios da humanização, com a assistência humanizada, com a mulher retomando ao seu papel de protagonista do seu próprio trabalho de parto, do seu próprio parir. (Entrevista 04)

A incorporação de novos conhecimentos e títulos aumenta o volume do capital do agente no campo e consequentemente de seu poder simbólico. O capital institucionalizado, aqui representado pelo certificado de especialista em enfermagem obstétrica, confere ao seu portador um valor convencional, constante, e juridicamente garantido, o que também repercute em sua posição ocupada na estrutura social(7).

Também os Congressos e Encontros foram importantes nesse processo, pois são lugares em que circulam muitos capitais, e isso propicia aos indivíduos a elaboração de ideias para a ação norteando suas práticas $^{(6)}$. Desse modo, as evidências científicas, tanto defendidas pelo modelo humanizado, apontavam que é importante valorizar aspectos do parto que o tornam menos intervencionista.

A episiotomia, por exemplo, é uma intervenção, uma incisão cirúrgica aplicada no períneo da mulher no momento da expulsão do feto, amplamente realizada no ambiente hospitalar, porém é um procedimento que não garante ou previne a ocorrência de lacerações perineais e pode gerar várias complicações e, em muitos casos, tal procedimento acontece sem o consentimento da mulher, não é valorizada sua opinião(14).

Esta intervenção no contexto da humanização foi considerada uma violação dos direitos sexuais e 
reprodutivos da mulher, assim como uma violência de gênero ${ }^{(15)}$. Diante desta concepção, muitas enfermeiras obstétricas pautaram seu cuidado no respeito ao princípio de que o parto é um evento fisiológico e sexual, do qual a mulher deve participar ativamente ${ }^{(12)}$. A partir daí incorporaram a proteção perineal e novas tecnologias de cuidado, de caráter não invasivo, para substituir as tecnologias invasivas ${ }^{(17)}$.

Eu sentia que cada vez que a gente ia a um novo congresso, a um novo encontro, a uma nova jornada, a gente voltava mais impregnada disso, e isso mudava até as nossas estatísticas, a gente começou a fazer menos episiotomia, a partir de determinado encontro de enfermagem. (Entrevista 06)

Depois que a gente começa a fazer as coisas, a ler, a participar de grupos a gente se contamina de algumas coisas, então a gente muda. (Entrevista 01)

Desse modo, a movimentação dos agentes entre diferentes campos sociais, as lutas travadas dentro do próprio campo ou, ainda, através de um processo de análise reflexiva sobre as próprias disposições ${ }^{(7)}$ proporcionada pelos Cursos de Especialização e nos Congressos, contribuíram para que essas enfermeiras transformassem sua prática. Deste modo, muitas enfermeiras passaram a reconhecer a mulher como protagonista no parto e nascimento:

O primeiro ponto que eu exploro na minha prática é de ter aquela mulher como a real mandatária, a real decididora, não sei se é essa a palavra, aquela que toma as decisões de como fazer, que fazer, que postura adotar. (Entrevista 04)

Como consequência deste princípio incorporado, começaram a diminuir as intervenções:

A gente passou a atuar para diminuir as intervenções desnecessárias [...] tentando diminuir o número de cesarianas desnecessárias e fazendo com que a gente adotasse outras práticas não medicamentosas. (Entrevista 02)

Essas medidas, apesar de não serem únicas, podem ter contribuído para reverter a imagem que se tinha do Brasil entre os anos de 1994 e 1996, em que o país apresentou uma das maiores taxas de cesáreas $(27,1 \%)$, quando comparadas a de outros países ${ }^{(18)}$. Ressaltamos que atualmente essas taxas continuam elevadas, apesar de já apresentarem uma diminuição considerável.

As enfermeiras entrevistadas passaram a crer na troca de conhecimentos para elaborar propostas que trazem conforto para as mulheres:

As pessoas não podem acreditar apenas naquilo que está no papel, [...] fazer sempre uma troca de conhecimento, porque não sou eu que trago o conhecimento do parto, é a mulher que traz para você. Então a gente tem que parar de ver tudo de dentro de um manual de assistência ao parto $e$ nascimento, quem vai trazer essa condição é a mulher. [...] Então a minha percepção hoje na enfermagem obstétrica é que você não só tem que trazer seu conhecimento, mas perceber o conhecimento do outro. [...] (Entrevista 09)

Quando as enfermeiras se permitiram reconhecer os conhecimentos do outro e suas respectivas necessidades, elas favoreceram a criação de um vínculo entre o profissional e a cliente, e dessa forma, implementaram elementos da humanização como o acolhimento da parturiente e de sua família ${ }^{(19)}$. Deste modo, passaram a valorizar a presença do acompanhante e mudança no ambiente e nas rotinas hospitalares:

A assistência ao parto, com acompanhante [...] um ambiente mais tranquilo [...] a mulher não precisava ficar sozinha, [...] o pré-parto não precisava ser uma sucursal do inferno, [...] a mulher não precisava ficar despida de nome, de roupa, de tudo. (Entrevista 08)

A participação do acompanhante no momento do parto, respaldada pela Lei 11.108 , de abril de 2005, é de fundamental importância, pois assim é possível recuperar a afetividade, a referência familiar e emocional, tão fragilizadas no ambiente hospitalar. E a inclusão do pai, neste cenário, aumenta ainda mais o vínculo familiar, reduz as tensões e favorece a segurança da mulher no trabalho de parto(19-20).

A proposta dos programas de humanização abrange, principalmente, a mudança de postura/atitude dos profissionais. Neste sentido, algumas enfermeiras aprenderam a ouvir a parturiente para transformar suas próprias ações de cuidado(1): 
Hoje eu sou muito mais de ouvir do que de falar, então nesse cuidado a gente tem que aprender a ouvir e a partir dessa escuta a gente transformar as ações. (Entrevista 09)

Para que o saber em saúde seja construído de maneira humanizada, é preciso estabelecer o diálogo franco, uma escuta ativa das subjetividades inerentes ao ser mulher e desenvolver a sensibilidade ${ }^{(1)}$. Desse modo, as enfermeiras pesquisadas identificaram a importância de saber falar, pois perceberam que mudaram sua maneira de falar e passaram a respeitar também o corpo da mulher, estimulando-a na participação em seu cuidado:

Comecei a conversar com as mulheres, a maneira como se fala com as mulheres, como você recebe a mulher, explicar tudo. Explicar tudo o que vai fazer, pedir licença de tocar na mulher. Fazer com que ela participe daquilo, eu acho importante e fundamental, para questão da humanização. (Entrevista 08)

Este processo instituído chama-se de acolhimento que implica em receber a mulher quando ela chega à unidade de saúde, responsabilizando-se por ela, ouvindo suas queixas, permitindo que ela expresse suas preocupações, angústias, garantindo atenção resolutiva e articulação com os outros serviços de saúde para a continuidade da assistência, quando necessário(1,13).

Desde que começou essa história da humanização do parto, que a gente foi inserindo tecnologias, podemos proporcionar conforto à mulher, confiança nela mesma, empoderamento. Acho que tem muita relação com o processo da humanização, acho que ajudou muito, dentro do campo obstétrico, até nas práticas do enfermeiro. (Entrevista 02)

Com a escuta ativa das expressões verbais e não verbais da parturiente e valorização dos sentimentos, medos e suas inquietações é possível aos poucos realizar ações de encorajamento, no exercício da autonomia e do empoderamento da mulher no parto e nascimento(1).

Com a implementação das práticas pautadas nos princípios da humanização, como, por exemplo, o estímulo à presença do acompanhante no processo do nascimento, a liberdade de deambulação e a possibilidade de ingerir líquidos são resgatados aspectos fundamentais dos direitos reprodutivos e sexuais que favorecem o andamento do parto e nascimento(21) sem intervenções. Tanto que, na visão dessas enfermeiras a episiotomia se tornou um procedimento agressivo ${ }^{(14-15)}$ :

Eu acho que a episiotomia é uma prática muito agressiva para a mulher. Então você ver a mulher com aquele períneo todo cortado, muitos pontos, isso pra mim é agressivo. (Entrevista 11)

A episiotomia no contexto da humanização realmente foi considerada uma violação dos direitos sexuais e reprodutivos da mulher, assim como uma violência de gênero(14-15,21). Diante desta concepção, muitas enfermeiras obstétricas pautaram seu cuidado no respeito ao princípio de que o parto é um evento fisiológico e sexual, do qual a mulher deve participar ativamente. A partir daí incorporaram a proteção perineal e novas tecnologias de cuidado, de caráter não invasivo, para substituir este procedimento.

\section{CONSIDERAÇÕES FINAIS}

Ao descrever o processo de aquisição pelas enfermeiras das práticas obstétricas frente à implantação do modelo humanizado em maternidades públicas do Rio de Janeiro observamos que um grupo de enfermeiras obstétricas incorporaram habilidades específicas advindas de novos conhecimentos que foram agregados em seu habitus.

Esses conhecimentos foram adquiridos na escola por meio de Cursos de Especialização; no local de trabalho ao vivenciarem as lutas travadas para implantar o Programa de Humanização do Parto e Nascimento nas maternidades do Rio de Janeiro e também pela participação do grupo pesquisado em Congressos, local que circula muito capital científico, e por isso mesmo, propicia a reflexão das práticas pelos profissionais.

Os conhecimentos adquiridos frente a esse processo direcionaram a prática obstétrica das enfermeiras no sentido de estimular o protagonismo da mulher, a fisiologia do parto e respeitar a privacidade da mulher. Em muitas maternidades essas agentes geraram práticas onde a decisão compartilhada e a preservação do corpo feminino, assumiram o lugar das relações assimétricas e das intervenções sem necessidades, como a episiotomia de rotina.

Diante do exposto, podemos concluir que as ações de manutenção, nos serviços de saúde, das estruturas que 
sustentem os princípios das práticas humanizadas no parto e nascimento, são de fundamental importância para que as enfermeiras continuem trabalhando e lutando no

\section{REFERÊNCIAS}

1. Porfírio $A B$, Progianti JM, Souza DOM. As práticas humanizadas desenvolvidas por enfermeiras obstétricas na assistência ao parto hospitalar. Rev. Eletr. Enf. [Internet]. 2010 [cited 2012 jan 12]; 12(2):331-6. Avaliable from: http://www.fen.ufg.br/revista/v12/n2/v12n2a16.htm. 2. Organização Mundial da Saúde. Care in Normal Birth: A Practical Guide. Geneva: WHO; 1996.

3. Prata JA, Progianti JM, Pereira ALF. O contexto brasileiro de inserção das enfermeiras na assistência ao parto humanizado. Rev. enferm. UERJ. 2012; 20(1):105-10.

4. Brasil. Portaria GM 2.815 de 29 de maio de 1998. Inclui na tabela do SIH/SUS grupo de procedimentos para o parto normal realizado por enfermeiro obstetra e parteira e dá outras providências. Diário Oficial [da] República Federativa do Brasil. Brasília; 1998. [cited 1998 jun 12]. Available from: http://dtr2001.saude.gov.br/sas/gab1998.htm.

5. Progianti JM, Porfírio AB. Participação das enfermeiras no processo de implantação de práticas obstétricas humanizadas na maternidade Alexander Fleming (1998-2004). Esc Anna Nery. 2012;16(3):443-450.

6. Mouta RJO, Progianti JM. Estratégias de luta das enfermeiras da Maternidade Leila Diniz para a implantação de um Modelo Humanizado de Assistência ao Parto. Texto contexto - enferm. 2009;18:731-740.

7. Progianti JM, Mouta RJO. A enfermeira obstétrica: agente estratégico na implantação de práticas do modelo humanizado em maternidades. Rev. enferm. UERJ. 2009;17(2):165-9.

8. Cassab LA. História oral: miúdas considerações para a pesquisa em serviço social. Serv Soc Rev [online]. 2003 [acesso 2013 Jan 21]; 5(2). Disponível em:

http://www.uel.br/revistas/ssrevista/c v5n2 latif.htm

9. Bourdieu P. O Poder Simbólico. 14 ed. Rio de Janeiro: Bertrand Brasil; 2006.

10. Setton MGJ. A teoria do habitus em Pierre Bourdieu: uma leitura contemporânea. Rev. Bras. Educ.2002;20:60-70.

11. Thiry-Cherques HR. Pierre Bourdieu: a teoria na prática. Rev. Adm. Pública. 2006;40(1):27-53.

12. Camacho KG. A enfermeira obstétrica frente às transformações de sua prática consequente ao movimento de humanização do campo obstétrico hospitalar. [dissertation]. Rio de Janeiro: Faculdade de Enfermagem/UERJ; 2010. 130p.

13. Nascimento NM, Progianti JM, Novoa RI, Oliveira TR, Vargens OMC. Tecnologias não invasivas de cuidado no parto realizadas por enfermeiras: a percepção de mulheres. Esc Anna Nery. 2010;14(3):456-461.

14. Zanetti MRD, Petricelli CD, Alexandre SM, Torloni MR, Nakamura MU, Sass N. Episiotomia: revendo conceitos. FEMINA. 2009;37(7):361-71.

15. Progianti JM, Araújo LM, Ricardo JOM. Repercussões da episiotomia sobre a sexualidade. Esc Anna Nery. 2008;12(1):4549.

16. Seibert SL, Salgado APA, Vargens OMC, Progianti JM. Refletindo sobre as tecnologias não-invasivas de cuidado de enfermagem obstétrica. Recenf. Revista Técnico-Científica de Enfermagem. 2010;26(8):294-9.

17. Moura CFS, Lopes GT, Santos TCF. Humanização e desmedicalização da assistência à mulher: do ensino à prática. Rev. enferm. UERJ. 2009; 17(2):182-187. sentido de contribuir para a sustentação da política pública de humanização e de incentivo ao parto normal no campo obstétrico.

18. Osava RH et al. Caracterização das cesarianas em centro de parto normal. Rev Saude Pública. 2011; 45(6): 1036-43.

19. Santos JO, Tambellini CA, Oliveira SMJV. Presença do acompanhante durante o processo de parturição: uma reflexão. Rev. Min. Enferm. 2011; 15(3): 453-8.

20. Zani AV, Yamagida GAA. A importância da formação na percepção da equipe de enfermagem acerca da presença do acompanhante em sala de parto. Rev enferm UFPE [on line]. 2008 [cited 2012 jun 08]; 2(4):373-77. Avaliable from:

http://www.revista.ufpe.br/revistaenfermagem/index.php/revis ta/article/viewArticle/322.

21. Marques DM, Lemos A. Assistência pautada nos direitos sexuais e reprodutivos: uma condição para promover a saúde da mulher. Rev. Eletr. Enf. [Internet] 2011 [acesso em: 10 fev 2012]; 13(3):449-55.

Artigo recebido em 19/05/2012.

Aprovado para publicação em 27/05/2013.

Artigo publicado em 30/09/2013. 